\title{
UX Design Management: Type of Management Systems and Communication Strategies in Technology Industry
}

\author{
Mo Ya Ju',a, Lee Jiunde Jim ${ }^{2, b}$ \\ 1 Department of Communication, National Chiao Tung University, 300, Taiwan \\ 2 Department of Communication, National Chiao Tung University, 300, Taiwan \\ axyxy588@gmail.com \\ ${ }^{*}$ Mo Ya Ju
}

\begin{abstract}
Keywords: UX Management, User experience design management, Management systems, Design communication model, organization communication
\end{abstract}

\begin{abstract}
In last ten years, user experience design is getting more popular than it is used to be in the technology industry. Most of the big technology companies started to incorporating UX activities at every stage of a project and also some of them built their own user experience design team or department. To deliver valuable products to customers and achieve team goals, leaders of the UX team should know how to lead a productive team, influenc businesses to adopt user-centered design and communicate with team members and customers. Liker's Management systems outlined four systems of management to describe the relationship, involvement, and roles of managers and subordinates in industrial settings. The four management systems are:

Exploitative Authoritative, Benevolent Authoritative, Consultative System and Participative System. This article focuses on how leaders and UX designers solve problems with their communication strategies in different management systems. Twenty-three UX teams, including thirty leaders and team members were invited to join the interviews. The affinity diagram was applied to analysis the data of interviews and indicated what is the keywords in the interviews. Then, matching the keywords and communication strategies with the Key elements of four management systems. As the result, we build the UX design communication model that shows how UX team solved the problems with their communication strategies in different management systems and provides UX leaders and researchers some suggestions on UX management.
\end{abstract}

\section{以管理系統理論分析使用者經驗設計部門領導方式與組織溝通策略 --- 以兩岸科技產業為例}

\author{
*莫雅如 ${ }^{1, a}$ ，李俊德 2 \\ 1國立交通大學傳播研究所，新竹，台灣 \\ 2國立交通大學傳播研究所，新竹，台灣 \\ axyxy588@gmail.com \\ *莫雅如
}

關鍵詞: UX管理、使用者經驗設計管理、管理系統理論、設計溝通模型、組織溝通

中文摘要. 使用者經驗設計管理聚焦於與團隊內、各部門組織、客戶等的溝通協調，以解決 設計與業務問題。各部門中又倚靠主管的領導方式，與透過溝通能力以解決問題，帶領組織 完成共同目標，完成專案設計與生產。管理系統理論依照上下級的信任程度、交往程度、溝 
通程度、工作的獎懲程度與工作參與程度, 將管理方式分為四種: 民主參與式、民主協商式、 溫和專制式與專制權威式。而在過往研究中顯示, 組織溝通確實與組織領導與管理方式相關。 因此, 本研究預期以管理系統理論分析, 目前使用者經驗設計部門業務溝通流程中, 領導人 所扮演之角色以及其運用之組織溝通的策略，提供使用者經驗設計團隊在業務與管理中，虐 清溝通活動中的關鍵要素與策略, 並解決問題達成目標。本研究以質性訪談方式深入瞭解兩 岸前百大企業之UX團隊的組織結構、業務與業務中之溝通活動, 以親合圖方式整理訪談資料。 透過訪談兩岸二十三間企業與三十位UX團隊主管與成員, 搜集研究資料, 並以親合圖整理出 要素。再以管理系統理論分析領導方式及相關要素匹配, 進一步歸納各領導方式在溝通流程 中, 所使用的溝通策略, 建構出管理系統理論下的使用者經驗設計組織溝通模型。此模型試 圖以四大管理方式與其相對策略呈現溝通活動之細節, 期望提供UX團隊於業務執行與管理遭 遇問題時參考之解決方案。

\section{1. 研究動機與目的}

根據2011年CHI研討會中管理UX團隊一文（Rohn，2011）提到，過去三十年間UX主管 與研究人員, 在企業文化中歷經發展、成熟，有成功也有失敗，還面臨著科技、商業、經濟 與文化的挑戰, 而如何定義UX團隊的成功？UX團隊主管如何面對機會與挑戰？UX團隊運用 何種策略或方法與工程、行銷、業務等部門合作？等皆是UX團隊與主管所面臨到的管理問題。 設計過程中, 設計師會根據使用者研究結果與洞察, 提出對於專案之意見與看法, 在遇到業 務上異議時，更將提出證明加以說服，以解決問題達成團隊共同目標。而設計工作不單是一 位設計師能夠獨立完成, 通常會以團隊方式執行, 目的是透過成員的互動與交流，分享個人 之專業知識、研究結果與發現來激發創意（Mohrman, et al，1995）。Butler指出隨著設計專案 的展開, 團隊會開始進行「溝通」並面對一連串的「溝通問題」，包含誰需要去聽什麼、什 麼時候需要傾聽、如何說明設計給團隊聽等。當團隊執行的專案越來越多後, 會開始學習如 何獨立運作、知道要跟那個部門的窗口聯繫、以什麼策略去說, 才能精準地傳達設計理念, 達到成功並有效的溝通, 使專案得以推行。Tharon W. Howard更認為設計團隊真正的產品是 「溝通」, 團隊成員之間好的溝通可以激發創意, 並且讓團隊設計流程運作順利, 設計出新 的介面與研究, 而團隊主管的工作就是營造良好的情境, 讓成員能夠有足夠的機會進行有效 的溝通（Lund，2011）。Microsoft使用者經驗總監Lund（2011）也認為UX管理人員必須具備 解決問題的能力、系統性的思考與有效的溝通能力。本研究欲以管理系統理論為基礎, 分析 30個企業的使用者經驗組織管理方式, 並歸納了解管理者與組織成員, 如何透過溝通活動解 決業務上的問題，建立設計管理溝通模型，期望能夠為設計組織管理提供管理方向與建議。

\section{2. 文獻探討}

\section{1 管理系統理論}

大部分對於領導的定義皆假設，領導者是擁有社會影響力的，也就是在特定情境下能激 勵團隊達成特定目標的能力, 因此擁有領導能力更代表要有能解決問題的答案, 以及了解用 何種方法管理組織成員。學者（Bláha, Mateicius \& Kaňáková, 2005）整理管理學相關研究， 可依照對有效領導的定義，與解釋影響個體方式分為三種：一、解釋領導為個人特質與風格 的研究, 認為組織會因為領導者的特質而遵從之, 如: 特性理論（Trait Theories）; 二、分 析領導者的影響力, 研究注重在領導者的行為與其領導行為的型態, 如: 行為理論(Behavioral Theories); 三、分析領導者會因爲在不同情境中的管理行為, 有不同的功能性與角色, 如: 情境理論（Situation Theories)。Lewin、Lippitt與White（1943）最早將領導分為三種經典的類 型：獨裁式領導、放任式領導與民主式領導。至1961年，Rensis Likert（戴國良，2017）將過 去三個世紀的領導研究整理, 並出版「管理的新型態」一書, 提出最有效率的是參與式管理, 
並將其研究資料歸納出領導的四個系統, 稱為管理系統理論。系統一, 專制權威式: 領導者 高度中央集權，不相信下屬，因此所有決策都為其一人決定，以命令的方式傳達給下屬。領 導者需要有嚴格的自我紀律, 且對於下屬的意見毫無興趣。而下屬工作的動力皆來自於高度 的恐懼與擔心責罰, 並且很少給予獎勵。系統二, 溫和專制式: 領導者還是維持權威式管理, 但對於某些下屬有些微的信任, 會將較小的事情給予其決定權, 但下對上還是戒慎恐懼。系 統三、民主協商式: 對於下屬開始有較多的信任, 會授予其權力處理一般事務與決策, 重要 決策仍由領導者決定。但上司與下屬的交往較多, 獎勵也多餘懲罰。系統四、民主參與式: 領導者對於下屬相當信任，願意授權其做決策，聽取下屬之建議，並願意與下屬一起解決問 題、提高工作績效、達成目標。在台灣UX 設計管理模型初探（陳牧晴，2016）研究提及, 設計管理中, 溝通活動涉及領導人風格與組織類型, 卻未明確分類其領導方式與組織成員溝 通互動上之關係, 本研究欲以管理學基礎的四大管理系統, 分析各組織的管理系統類型, 並 指出各類型因是否因其信任度關係、獎勵制度的影響，而使用不同的溝通模式與策略。

\section{2 設計組織溝通}

在面臨全球產業變化與競爭之下，企業必須有效地管理組織，使組織成員達成共識，完 成組織目標，而組織溝通為其中最關鍵之要素（李元墩，1999）。Robbins（2000）指出員工 業務執行時, 大約投入 $70 \%$ 的時間在溝通活動中, 因此有效的溝通為現在組織成功的基礎(Von Krogh, Ichijo \& Nonaka，2000）。在UX設計流程中, 團隊成員與主管更肩負著溝通的責任， 以確保能將設計風格與概念應用在最終產品與服務（Detweiler，2007），因此，「溝通」為 UX設計業務與管理不可或缺之活動。學者Kwiakowska（2014）指出「溝通問題」若無法有 效的解決與管理, 將阻擾設計業務的進行, 如: 部門內與跨部門在洞見上的溝通上, 無法正 確傳達設計理念, 將造成設計專案無法執行。而Emmitt and Gorse（2007）認為UX主管帶領 團隊，並促進「有效溝通」是目前UX管理中的一大挑戰。在台灣UX 設計管理模型初探（陳 牧晴, 2016）研究中, 更進一步建議, 應更深入探討UX團隊「如何解決溝通問題」, 如何與 跨部門合作，設計組織主管領導方式，以何種方式爭取上級主管與其他部門之信任，才能為 利益相關人創造共同價值。Ashley \& Desmond (2005) 為UX團隊管理提出五大有效溝通之準 則, 包含: 團隊需要有常規化的溝通管道、溝通結果需要滿足管理階層、跨部門間協同合作 之機制、尊重不同文化差異、取得不同利益相關人之價值與認同。

\section{3. 研究方法}

本研究對於UX團隊管理者領導方式與溝通策略的探索，屬於初探性的研究，欲採用質性 研究中的深度訪談法, 以從實際業務與管理環境中, 得到更完整及深入的資料。本研究共訪 談23家企業，30位受訪者，受訪時間為2016年三月至2018年十一月。受訪企業挑選業界具代 表性之UX團隊，產業別以台灣主要的硬體產業居多，共12間台灣前二十大硬體公司。考量研 究涵蓋廣度及UX團隊發展之成熟度, 另外挑選各產業發展較成熟及完整之團隊, 包含: 網路 旅遊服務業、線上音樂產業、數位資訊業、電信業、顧問業、汽車業及休閒旅遊業，共11家 企業之UX團隊，其中2家企業為中國極具代表性之軟體與互聯網公司，期望對於目前大陸UX 團隊能有初探性的瞭解與研究。此外, 因顧及保密協同, 本研究不予公開受訪者詳細公司資 訊。訪談對象為UX團隊中階以上主管與資深UX設計師, 其職責為一般業務外, 還具有管理、 溝通、協調合作等管理職務, 以符合本研究目的, 瞭解UX主管領導方式與如何以溝通解決問 題。

\section{1 問卷設計}

本研究以Ashley \& Desmond（2005）五大溝通準則與溝通文獻為主，活動理論為架構， 將溝通活動分為: 目標、主體、社群、分工、規則, 工具等六大要素發展深度訪談問項, 探 
索兩岸UX團隊之「溝通活動」, 如何解決業務與管理中遇到之溝通問題, 為了何種目的而進 行溝通活動, 領導者在溝通進行中扮演何種角色, 並以何種策略進行有效的溝通。

\section{2 資料分析}

親和圖（Affinity Diagram）或稱KJ法（KJ Method），為將訪談、腦力激盪、回饋結果等 回收資料, 因其自然的關係而分類為群組的工具（Kawakita，1966），將具體描述的現象, 找出其關聯性形成抽象概念的組織化過程。研究以親和圖之方式整理訪談資料, 由三名相關 背景之研究生, 從訪談錄音檔與逐字稿中, 提取出關鍵字, 並進行討論, 將關鍵字分類命名。 模型的建立以管理系統理論為架構, 依照提取之要素, 判別該組織的管理系統為何, 且將其 溝通策略歸納，建立設計管理溝通模型。

\section{4. 研究結論與建議}

分析結果（如表 1) 大部分領導管理模式為溫和專制式, 共八個組織; 其次為民主參與 式, 共七個; 民主協調式, 共三個; 最後專制權威式為一個。根據 Liker（1967）的 The Human Organization一書建議, 民主參與式是最能將人力資源, 在組織中有效發揮的系統。其研究發 現大多組織都在系統二（溫和專制式）與系統三（民主協調式），並建議對於不同層級的主 管進行密集的領導訓練, 能轉換到民主參與式, 讓上下級能一起參與, 使組織能夠有效的運 作，且永續發展。本研究結果與 Liker 的系統管理研究相似，集中在系統二與四，且在不同 系統下, 也積極以溝通策略彌補領導上的不足。而系統三的組織, 與 Liker 的建議不謀而合, 以教育訓練、種子培飬, 將 UX 理念傳播至各部門, 期望組織成員皆能參與流程與決策, 邁 向係民主參與式的管理方向

表1 設計管理溝通模型

\begin{tabular}{|c|c|c|c|c|c|c|}
\hline \multirow{6}{*}{$\begin{array}{l}\text { 李 } \\
\text { 克 } \\
\text { 特 } \\
\text { 管 } \\
\text { 理 } \\
\text { 系 } \\
\text { 統 } \\
\text { 理 } \\
\text { 論 }\end{array}$} & \multicolumn{2}{|c|}{ 組織變數 } & 系統一 & 系統二 & 系統三 & 系統四 \\
\hline & \multirow{3}{*}{$\begin{array}{l}\text { 上 } \\
\text { 級 } \\
\text { 繝 } \\
\text { 系 }\end{array}$} & 信任程度 & 對下屬無信心 & 主僕關係 & 上下屬有一定的信任 & 完全信任 \\
\hline & & 交往程度 & $\begin{array}{c}\text { 幾乎沒有交往、交往感到 } \\
\text { 恐懼與不信任 }\end{array}$ & $\begin{array}{c}\text { 屈就領導者, 下屬仍戰戰兢 } \\
\text { 兢應對 }\end{array}$ & 適度的日常業務往來 & 較熱絡深入的交往, 互相依賴程度高 \\
\hline & & 溝通程度 & 較不溝通 & 一定程度的溝通 & 較多溝通 & 完全溝通 \\
\hline & \multirow{2}{*}{$\begin{array}{l}\text { 宱 } \\
\text { 激 } \\
\text { 勵 }\end{array}$} & 獎懲程度 & 恐嚇威脅與極少的報酬 & 有報酬，還是有懲罰 & 報酬與少數的懲罰 & $\begin{array}{c}\text { 優厚的報酬 } \\
\text { 與自我反省覺知 }\end{array}$ \\
\hline & & 參與程度 & 上級命令,下屬遵守 & 會聆聽下屬建議 & 下屬能夠有日常事務的決定權 & 下屬能參與決策並完全控制流程 \\
\hline $\begin{array}{l}\text { 訪 } \\
\text { 談 } \\
\text { 資 } \\
\text { 料 }\end{array}$ & \multicolumn{2}{|c|}{$\begin{array}{l}\text { 實際案例 } \\
\text { 與溝通策略 }\end{array}$} & $\begin{array}{l}\text { 企業Q:主管命令影響設計 } \\
\text { 方向與產品, 不同部門間 } \\
\text { 很難進行溝通, 通常都是 } \\
\text { 因為上級指示而合作。跨 } \\
\text { 集團間有也相同設計組 } \\
\text { 織, 卻沒有一致的設計流 } \\
\text { 程與理念。 }\end{array}$ & 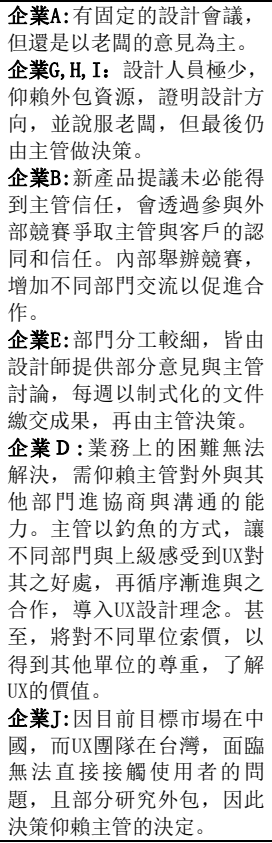 & 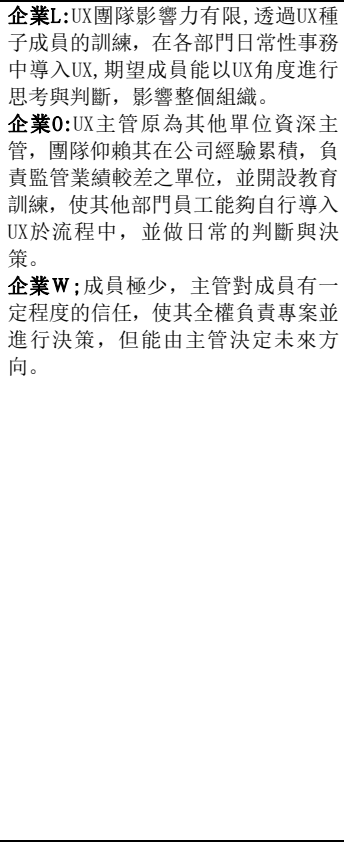 & $\begin{array}{l}\text { 企業F, S: 設計部門與最高長官能直 } \\
\text { 接通, 除了現有產品開發外, 以墢 } \\
\text { 展未來產品概念為目標, 成員皆為資 } \\
\text { 深設計師, 能參與決策及領導團隊開 } \\
\text { 發產品。 } \\
\text { 企業C, R, T: 設計組織為分散型, 設計 } \\
\text { 師被派至各組織, 其除了專業外, 必 } \\
\text { 須具有一定的專案管理能力, 能獨自 } \\
\text { 做判斷與決策, 並與不同階層主管定 } \\
\text { 期會議, 以參與開發流程與決策。 } \\
\text { 企業N, U; 擁有一套特殊開發工具, 設 } \\
\text { 計師皆可透過此工具進行設㺞決 } \\
\text { 策。 }\end{array}$ \\
\hline
\end{tabular}

理論架構圖來源：翻譯整理自R. Likert, The Human Organization (1967), P.4 


\section{References}

[1] Rohn, J., \& Wixon, D., Managing user experience teams: lessons from case studies, establishing best practices, Paper presented at the CHI'11 Extended Abstracts on Human Factors in Computing Systems, 2011

[2] Mohrman, S. A., Cohen, S. G., \& Morhman Jr, A. M.,Designing team-based organizations: New forms for knowledge work: Jossey-Bass, 1995

[3] Lund, A., User experience management: essential skills for leading effective UX teams: Elsevier, 2011

[4] Bláha, J., Mateicius, A., Kaňáková, Z., Personalistika pro male a střední firmy, CP Books, a.s., Brno, 2005

[5] Tai, Kuo-liang, Business Administratio - Case study, Wu-Nan Book Inc., P.261, 2017

[6] Chen,Mu-ging, The Management Model Development of User Experience Design in Organization -A Case Study for Taiwan Technology Industry, 2016

[7] Yuan-Duen Lee, Retrospect and Prospect in Organizational Communication Studies, Journal of Chinese Management Review, Vol.2, No.5, pp.121 131, 1999

[8] Robbins, S. P., Organizational Behavior. Upper Saddle River. NJ: Perntice Hall Inc.,2001

[9] Von Krogh, G., Ichijo, K., \& Nonaka, I., Enabling knowledge creation: How to unlock the mystery of tacit knowledge and release the power of innovation: Oxford University Press on Demand, 2000

[10] Detweiler, M.,Managing UCD within agile projects. interactions, 14(3), 40-42, 2007

[11] Kwiatkowska, J., Szóstek, A., \& Lamas, D., Design and Business Gaps: From Literature to Practice. Paper presented at the Proceedings of the 2014 Mulitmedia, Interaction, Design and Innovation International Conference on Multimedia, Interaction, Design and Innovation, 2014

[12] Emmitt, S., \& Gorse, C.,Communication in construction teams: Routledge, 2006

[13] Ashley, J., \& Desmond, K.,Success with user-centered design management. interactions, 12(3), 27-32, 2005

[14] Kawakita, J.,The original KJ method. Tokyo: Kawakita Research Institute, 1991

[15] Likert, R., The human organization: its management and values, 1967 